\title{
COVID-19, Modern Pandemic: A Systematic Review From Front-Line Health Care Providers' Perspective
}

\author{
Mamtha Balla ${ }^{\mathrm{a}, \mathrm{i}}$, Ganesh Prasad Merugu ${ }^{\mathrm{b}}$, Mitra Patel ${ }^{\mathrm{c}}$, Narayana Murty Kodurid, \\ Vijay Gayam ${ }^{\mathrm{e}}$, Sreedhar Adapa ${ }^{\mathrm{f}}$, Srikanth Naramalag, Venu Madhav Konala ${ }^{\mathrm{h}}$
}

\begin{abstract}
Coronavirus disease 2019 (COVID-19) caused infection in 168,000 cases worldwide in about 148 countries and killed more than 6,610 people around the world as of March 16, 2020, as per the World Health Organization (WHO). Compared to severe acute respiratory syndrome and Middle East respiratory syndrome, there is the rapid transmission, long incubation period, and disease containment is becoming extremely difficult. The main aim of this systematic review is to provide a comprehensive clinical summary of all the available data from high-quality research articles relevant to the epidemiology, demographics, trends in hospitalization and outcomes, clinical signs and symptoms, diagnostic methods and treatment methods of COVID-19, thus increasing awareness in health care providers. We also discussed various preventive measures to combat COVID-19 effectively. A systematic and protocol-driven approach is needed to contain this disease, which was declared as a global pandemic on March 11, 2020, by the WHO.
\end{abstract}

Keywords: COVID-19; Systematic review; Pandemic; nCOVID; Severe acute respiratory syndrome; Middle East respiratory syndrome

Manuscript submitted March 21, 2020, accepted March 25, 2020

aDepartment of Internal Medicine, University of Toledo and Promedica Toledo Hospital, Toledo, $\mathrm{OH} 43606$, USA

bivision of Geriatric Medicine, Department of Family Medicine, University of Toledo, OH 43614, USA

'Department of Internal Medicine, University of Toledo, OH 43614, USA

${ }^{\mathrm{d} D e p a r t m e n t}$ of Psychiatry, Great Plains Health, 600 W Leota, North Platte, NE 69101, USA

eDepartment of Medicine, Interfaith Medical Center, Brooklyn, NY, USA

fDepartment of Internal Medicine, Division of Nephrology, Adventist Medical Center, Hanford, CA 93230, USA

gDepartment of Internal Medicine, Division of Rheumatology, Adventist Medical Center, Hanford, CA 93230, USA

hDepartment of Internal Medicine, Divison of Medical Oncology, Ashland Bellefonte Cancer Center, 122 St Christopher Dr, Ashland, KY 41169, USA

${ }^{\mathrm{i} C}$ Corresponding Author: Mamtha Balla, Department of Internal Medicine, University of Toledo, Promedica Toledo Hospital, Toledo, OH 43606, USA.

Email: athamam@gmail.com

doi: https://doi.org/10.14740/jocmr4142

\section{Introduction}

Coronavirus disease 2019 (COVID-19) infection, which is a global pandemic declared on March 11, 2020, by World Health Organization (WHO), was reported to have infected 168,000 cases worldwide in about 148 countries and territories and killed more than 6,610 people around the world as of March 16, 2020 [1]. There is a rapid transmission, long incubation period, and the containment of the disease is extremely difficult compared to prior epidemics of severe acute respiratory syndrome (SARS) and Middle East respiratory syndrome (MERS) [2].

There is a paucity of literature on this pandemic as it is novel. We aimed to provide a concise clinical summary of all the quality data relevant to the epidemiology, trends in hospitalization and outcomes, clinical signs and symptoms, diagnostic and treatment methods of COVID-19, thus increasing awareness in health care providers at the front-line. We also discussed various preventive measures to combat and contain COVID-19 effectively.

\section{Literature Search Methods}

We conducted a systematic search of published articles from PubMed, google scholar databases and in-press literature from google search engine through snowballing. There were two independent reviewers, each focusing on COVID-19, novel coronavirus (nCoV), SARS and MERS, and third independent reviewer to resolve any conflicting article of interest. We used the keywords as mentioned above and after stringent exclusion criteria, a total of 58 articles, including reports from the trusted newspapers and websites. Most of the articles were single case reports, multiple case studies and systematic reviews (11 retrospective studies, one meta-analysis, three systematic reviews, six case series, five case reports, five newspapers, 24 science research articles, and rest 3 reference's from official websites).

\section{Epidemiology}

The initial cases were strongly associated with the Huanan seafood market, in which exotic animals were sold for food [3]. According to $\mathrm{Lu}$ et al, the virus (termed SARS-CoV-2) shares $88 \%$ sequence identity to two coronaviruses found in bats, bat- 


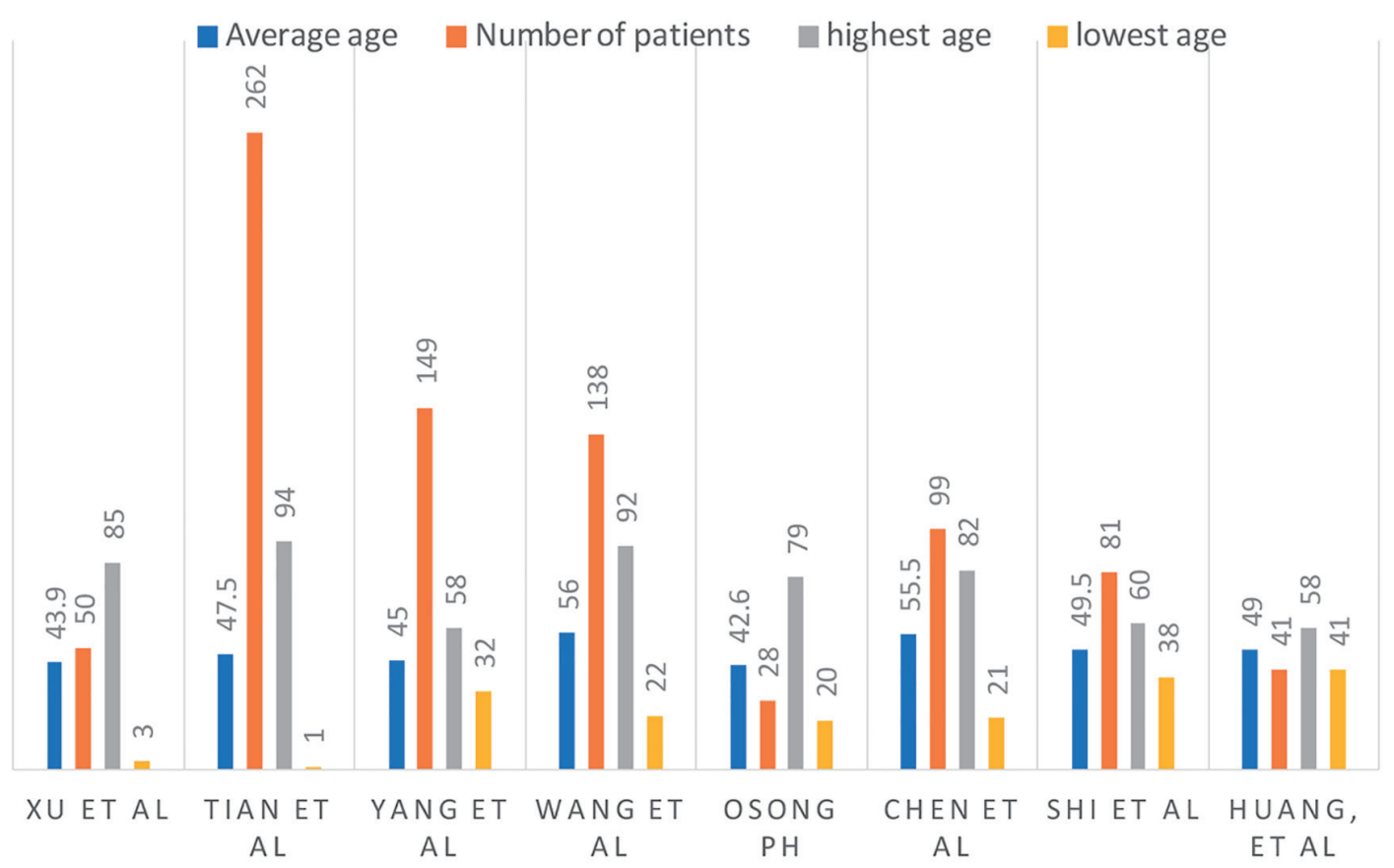

Figure 1. Number of patients, average age and age range.

SLCoVZC45 and bat-SL-CoVZXC21, 79\% identity with the SARS coronavirus and $50 \%$ identity with MERS coronavirus $[4,5]$. According to Chan et al, SARS-CoV-2 is thought to be transmitted via contaminated hands, surfaces and aerosolized droplets, and extensive human-to-human transmission is evident [6].

According to $\mathrm{Li}$ et al, the average incubation period is 5 days but is highly variable and can last up to 2 weeks [7]. SARS$\mathrm{CoV}-2$ is thought to have originated from bats and transmitted to humans from an intermediate host, civets and dromedary camels, respectively. Still, no source or intermediate host has been confirmed yet via genome sequencing and phylogenetic analysis [2]. This hypothesis was made because previous coronavirus strains have originated from the Rhinolophus affinis bat [8]. However, Xiao et al reported the isolation and characterization of a 2019-nCoV-like coronavirus from pangolins (Manis javanica) [9]. Similarly, in October 2019, a viral metagenomic study of pangolins identified severe acute respiratory syndrome-coronavirus (SARS-CoV)-related sequences $[10,11]$. According to the study by Xu et al, $60 \%$ of people diagnosed with COVID-19 had traveled to Wuhan or nearby regions $(60 \%), 36 \%$ had close contact with novel coronavirus pneumonia (NCP) patients and $4 \%$ had no definite exposure [12]. According to the study by Tian et al, $40.5 \%$ of people diagnosed with COVID-19 had traveled to Wuhan or nearby regions [13]. Beijing is the fourth mostaffected city in China [13].

\section{Age Distribution}

According to $\mathrm{Xu}$ et al, their patients with mild, common and severe COVID-19 were of mean ages of 44 years, 55 years and 66 years, respectively [12]. The age distribution of COVID-19 diagnosed patients in the study by Tian et al included ages < $1(1 \%), 1-12(3 \%), 13-44(43 \%), 45-64(35 \%)$ and $>65(18 \%)$ [13]. Liu et al described COVID-19 in children. They analyzed a total of 366 hospitalized patients, and $6 \%$ (six patients) of them were positive for COVID-19. According to Huang et al and Chen et al, SARS-CoV-2 seems to have a predilection for the elderly male population and patients with comorbidities $[14,15]$. According to the study published in Osong public health and research perspectives, 7\% of the population were greater than 60 years of age, and 93\% were less than 60 years of age [16]. These findings are summarized in Figure 1.

\section{Gender}

Males are experiencing a higher rate of incidence and case fatality compared to females [17]. In a study reported from South Korea, 46\% were females and 54\% were males [16]. These results for multiple studies are summarized in Figure 2.

\section{Clinical Signs/Symptoms}

$\mathrm{Xu}$ et al analyzed 50 patients with COVID-19 confirmed cases and symptoms included fever (42\%), cough (20\%), expectoration $(14 \%)$, fatigue $(16 \%)$, headache $(10 \%)$, gastrointestinal discomfort (2\%), shortness of breath (SOB) $(8 \%)$ and muscle ache $(16 \%)$ [12]. Fever is the most common symptom [12]. 


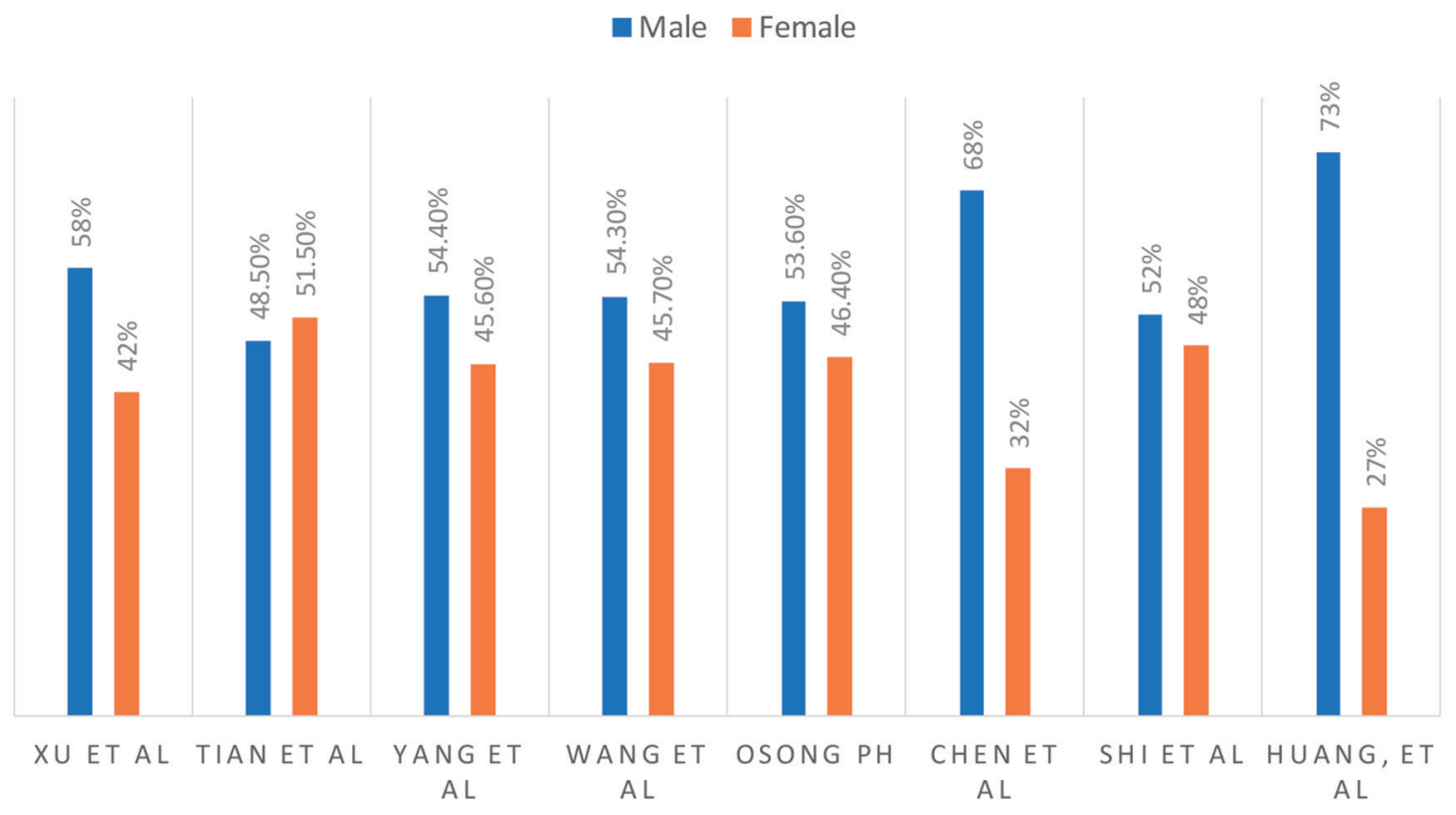

Figure 2. Male and female ratio.

Tian et al analyzed 262 cases of real-time reverse transcriptase polymerase chain reaction (RT-PCR) confirmed COVID-19 in China and symptoms included fever $(82 \%)$, cough $(46 \%)$, fatigue $(26 \%)$, SOB (7\%) and headache $(6 \%)$ [13]. In severe cases, SOB was present in $32.6 \%$ of the patients. Tian et al reported that the median time of incubation was approximately 7 days [13]. The median time from onset of illness to a hospital visit and hospital visit to the defined confirmed case were 4.5 and 2.1 days, respectively [13]. Yang et al analyzed 149 cases of RT-PCR confirmed COVID-19 in China and symptoms included fever $(76 \%)$, cough $(58 \%)$, expectoration $(32 \%)$ and SOB (1\%) [18]. However, a significant number of patients do present with atypical symptoms [19], including nausea, vomiting (1-3\%) and diarrhea $(2-10 \%)[3,15]$.

Chen et al analyzed 99 patients in a retrospective single-center study in Wuhan, and patients presented with fever $(83 \%)$, cough $(82 \%)$, SOB $(31 \%)$, muscle aches $(11 \%)$, confusion $(9 \%)$, headache $(8 \%)$, sore throat $(5 \%)$, rhinorrhea $(4 \%)$, chest pain $2 \%$, diarrhea $(3 \%)$, nausea and vomiting (1\%) [15]. According to Wang et al, even though fever is the most common symptom of COVID-19, the absence of fever in COVID-19 cases is more frequent than in SARS-CoV and MERS-CoV infection [20]. Lillie et al presented a case where symptom onset started with fever, which then progressed to sore throat and dry cough followed by diffuse myalgia [21].

According to the study published in Osong public health and research perspectives, they analyzed the first 28 cases reported in South Korea. Out of 28 patients, 32\% reported fever and sore throat, $18 \%$ cough with or without sputum, $18 \%$ chills, $14 \%$ muscle aches, $11 \%$ generalized weakness and $11 \%$ headache at the time of presentation. Moreover, 64\% developed pneumonia. The incubation period was 4.6 days [16].

Luo et al analyzed 83 patients confirmed with COVID-19 infection in Anqing, China; of these, eight patients were asymptomatic at confirmation, one of whom did not develop any signs or symptoms during the entire 17-day hospitalization. This patient was a 50-year-old female with no comorbidities. Despite her negative labs and radiological tests, her throat swabs and anal swabs were positive of virus nucleic acid for at least 17 days, indicating that healthy carriers are very likely a possibility [22]. Hu et al [23] described clinical characteristics in 24 asymptomatic patients after screening among close contacts in Nanjing, China. Out of 24 patients, seven patients did have a normal computed tomography (CT) and had no symptoms during their entire hospitalization. The median age of these seven patients was 14 years younger than the rest of the patients. The median communicable period is defined as the first day of a positive nucleic acid test to the first day of the negative nucleic acid test. It can be up to 21 days in asymptomatic patients [23].

A case report describing the first case of Canada showed that the patient had symptoms of hemoptysis on days 2 through 6 along with fever and non-productive cough on presentation [24]. Lillie et al presented a case where symptom onset started with fever, which then progressed to sore throat and dry cough followed by diffuse myalgia. This seems to be the most consistent pathway of symptom onset [21].

The most common symptoms include fever (83\%), cough (82\%) and breathlessness (31\%) [3]. According to the Chinese Centers for Disease Control and Prevention (CDC), $81 \%$ of infections were considered mild and only $1.2 \%$ asymptomatic [3]. According to Huang et al, the current published data indicate a long mild incubation period followed by rapid progression of the disease with 8 days being the median time from initial symptoms to the onset of breathlessness, 9 days to acute respiratory distress syndrome (ARDS) and 10 days to admission to the intensive care [14].

The clinical signs and symptoms from different studies 


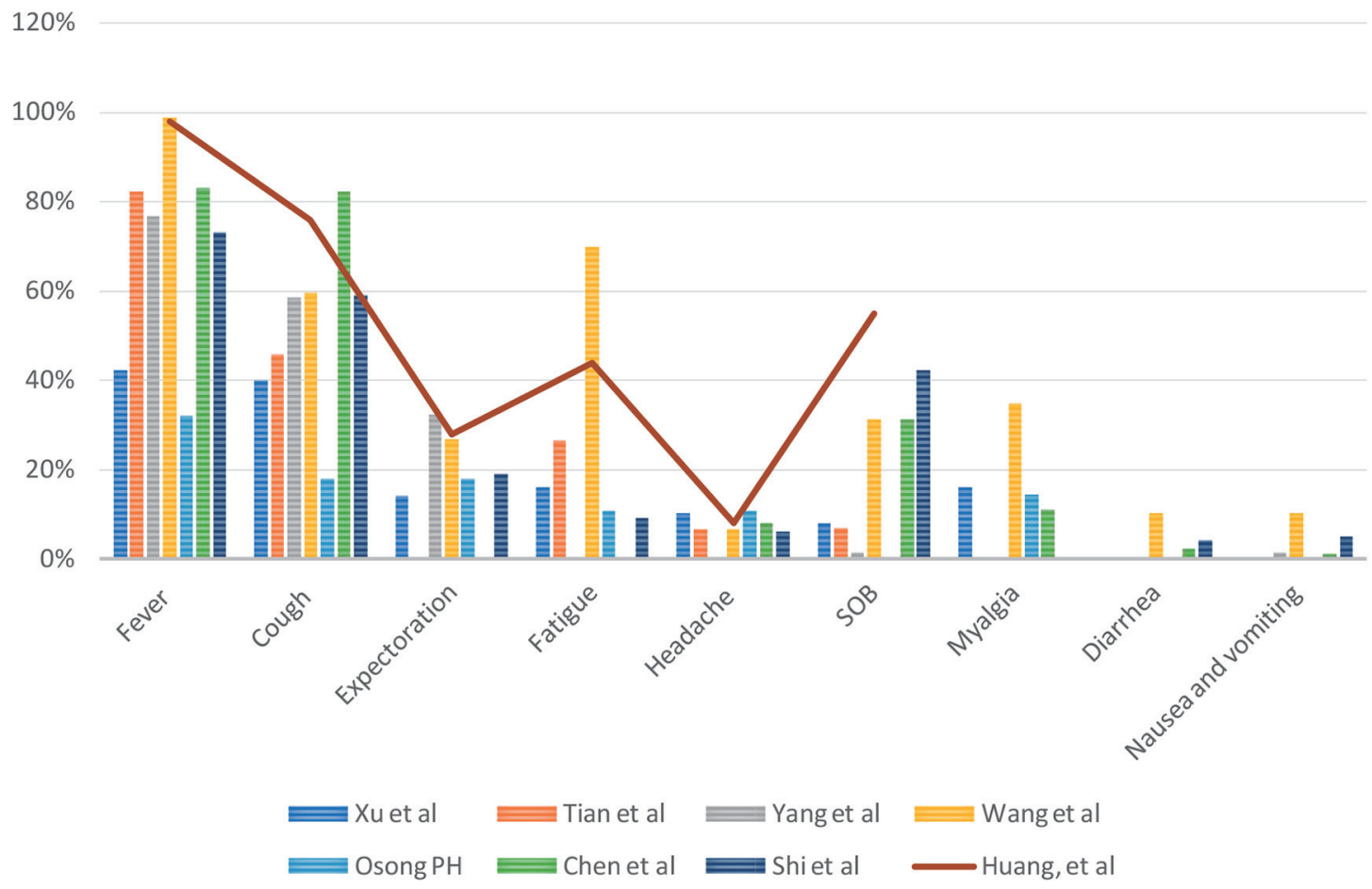

Figure 3. Clinical signs and symptoms.

are summarized in Figure 3 and temperature at presentation in centigrade is summarized in Figure 4.

\section{Laboratory Testing}

COVID-19 is diagnosed via RT-PCR $[12,13,25]$. Multiple sources found that a normal to slightly reduced leukocyte count occurred in patients with COVID-19 (98\%) [12, 25]. $\mathrm{Xu}$ et al reported a decreased lymphocyte count in $28 \%$ of their patients [12], while Yang et al reported leukopenia and lymphopenia in $24 \%$ and $35 \%$ of their patient population respectively [18]. An elevated C-reactive protein (CRP) was reported in $52-55 \%$ of the patients $[12,18]$. Thrombocytopenia

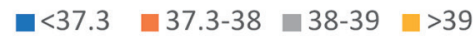

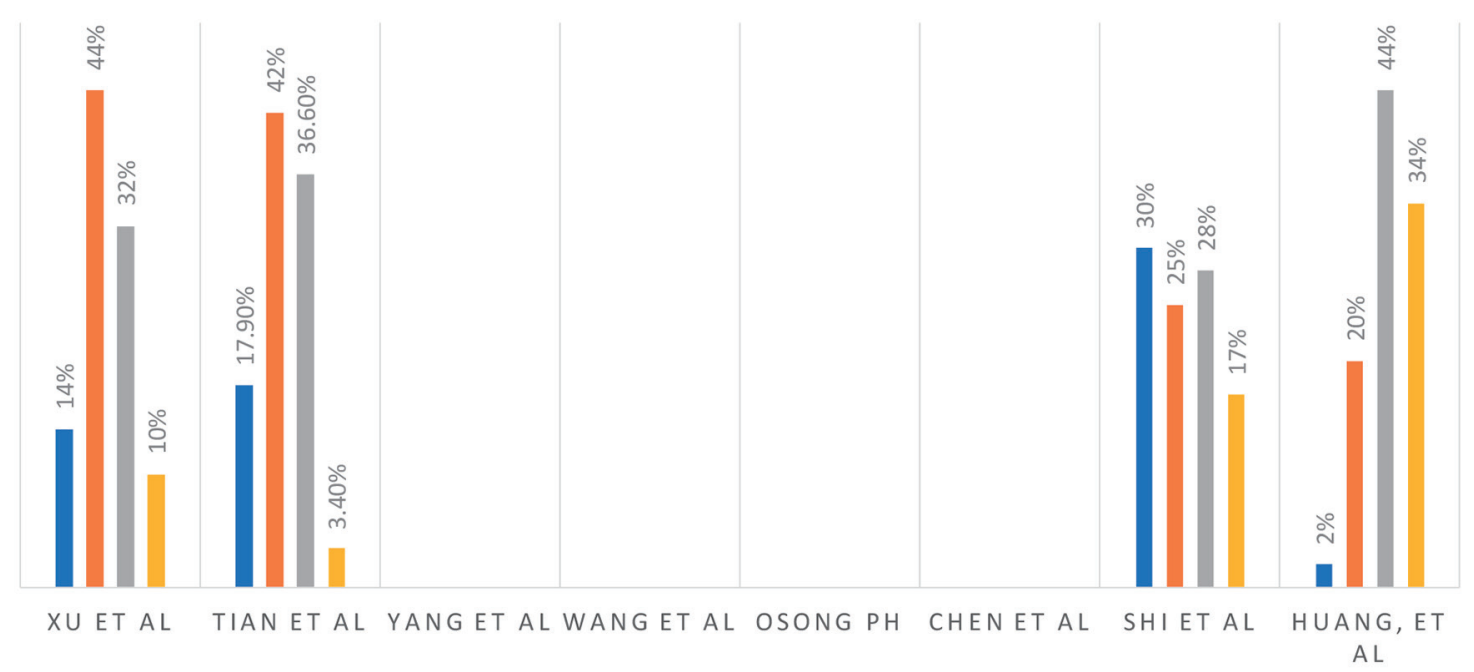

Figure 4. Temperature in centigrade at presentation. 


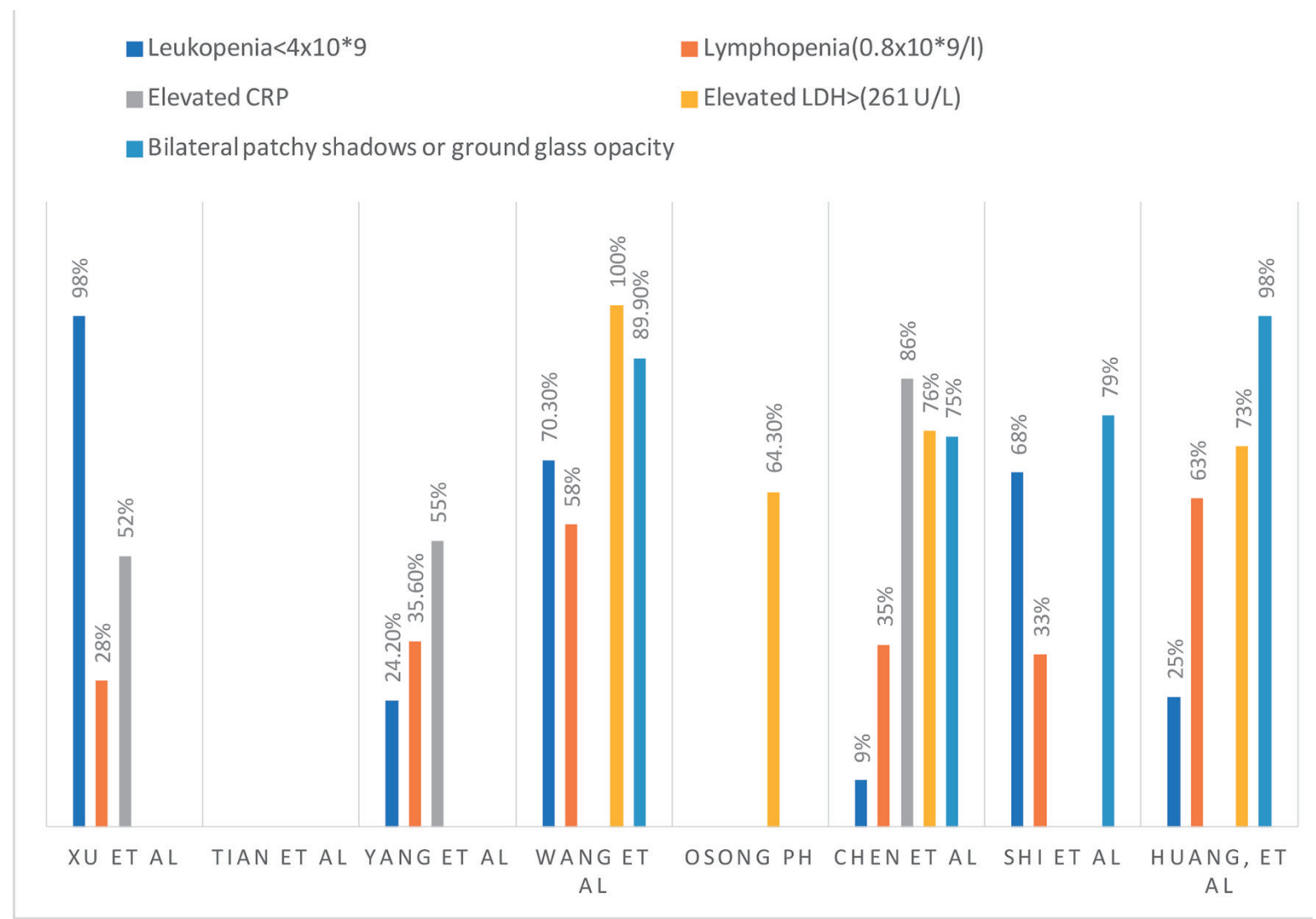

Figure 5. Laboratory and radiological findings.

was seen in $13 \%$ of patients. Acute kidney injury was present likely due to dehydration, not from the virus directly [21]. According to the meta-analysis done by Lippi et al, elevated procalcitonin levels were associated with almost five-fold increased risk of severe COVID-19 infection (odds ratio (OR): 4.76; 95\% confidence interval (CI): 2.74 - 8.29). They advised that serial measurements of procalcitonin may play a pivotal role in analyzing the worsening of the disease to more severe form [26].

According to the case report by Ruan et al, they found a patient with a negative nucleic acid test, tested twice 8 days apart. As the patient was showing typical CT imaging patterns suspicious for COVID-19 and deterioration of symptoms, repeat testing on day 11 was positive. As exact biological characteristics of COVID-19 are still not defined well, multiple sampling from multi-sites for the highly suspected population can be useful for COVID-19 detection at a much earlier stage [27]. Specimens should be tested for routine bacterial and viral infections, as well as using both upper and lower respiratory tract samples to test for SARS-CoV-2 [3]. Serological tests are in development, and they can be used if RT-PCR is not available [3]. As per the case reported by Chen et al, the oropharyngeal swab test of COVID-19 RNA turned positive even during the convalescence period in a confirmed case; it emphasizes the significance of active surveillance of COVID-19 RNA for inactivity assessment [28].

The laboratory results from different studies are summa- rized in Figure 5.

\section{Imaging}

According to Zhang et al, in a month, out of 1,467 suspected patients suspected of coronavirus pneumonia, 152 patients $(10 \%)$ had typical imaging findings or positive nucleic acid tests [29]. Chest CT is an important tool for diagnostic for lung diseases. Combining imaging with clinical and laboratory findings could facilitate early diagnosis of COVID-19 pneumonia. Because the time of onset of symptoms to ARDS can be as short as 9 days, early recognition of the disease is therefore essential for management.

In a retrospective study done in Wuhan on 81 patients from December 20, 2019 to January 23, 2020, they were able to describe the characteristics of the chest CT at specified time points during the disease course. They have divided the patients into four different groups, as shown in Table 1 [30]. Based on the review, COVID-19 pneumonia is described radiographically as bilateral, subpleural ground-glass opacities with air bronchograms, ill-defined margins and slight predominance on the right lower lobe. It was also noted that the radiological evolution of COVID-19 pneumonia is consistent with the clinical course of the disease. Therefore, serial CT could help monitor disease progression. The study also pointed out that patients with old age, male and with underlying comorbidities as well 
Table 1. Group Staging Based on Chest CT Findings From a Retrospective Study on 81 Patients

\begin{tabular}{lll}
\hline Groups & Duration of symptoms & CT chest findings \\
\hline Group 1 & Subclinical & Unilateral ground-glass opacities \\
Group 2 & Less than 1 week & Bilateral ground-glass opacities \\
Group 3 & $1-2$ weeks & Decrease in ground-glass opacities \\
Group 4 & $2-3$ weeks & Consolidation and mixed patterns \\
\hline
\end{tabular}

CT: computed tomography.

as progressive radiographic deterioration on follow-up are the risks for poor prognosis [30]. According to Chen et al, the majority $(75 \%)$ of patients had bilateral pneumonic changes on CT imaging [15]. Guan et al reported 230 out of $1,099(20 \%)$ cases [31], and Chung et al reported three out of $21(14 \%)$ have normal CT scans for patients diagnosed with symptoms along with confirmation of infection with RT-PCR [32]. According to a single-center study done by Chen et al in 99 patients, $75 \%$ of patients showed bilateral pneumonia, ARDS developed in $17 \%$ and $11 \%$ of them died with multi-organ failure [15].

As per the review of literature, the CT scans of the chest showed lesions or abnormalities more commonly found in bilateral lower lobes with the right middle lobe least affected. Multilobar involvement was seen in $96-98 \%$ of the patients $[12,25,33]$. The lesions are mostly located in the peripheral area under the pleura with possible extension into the pulmonary hilum $(36 \%$ in the periphery and $2 \%$ in the center of the lung) $[12,18,25]$. These lesions sometimes were accompanied by air bronchograms but rarely pleural effusions [12, 33]. Regarding lobar involvement, right lower lobe is most commonly involved in approximately $95 \%$ of cases followed by left lower lobe $(88 \%)$, left upper lobe $(80 \%)$ and right upper lobe $(73 \%)$ [12]. Pneumothorax, as well as bilateral pleural effusions, was identified only in $1 \%$ of the patients $[25,33]$. Approximately $11 \%$ of the patient had normal CT findings.

CT findings based on the stage of the disease are as follows [12]: 1) Mild novel coronavirus pneumonia patients have no abnormalities seen on a CT scan. 2) The early-stage infection which is more common has ground-glass opacities identified in the periphery and about $75 \%$ of the patients, mixed groundglass opacity along with consolidation in approximately $53 \%$ of the patients, nonuniform density with air bronchograms in about 53\% and thickened interlobular/intralobular septa in $75 \%$ of the patients. 3) Patients who are severe or critically ill have multiple patches of ground-glass opacities as well as consolidation in approximately $69 \%$ of the patients and mixed findings in about $77 \%$ of the patients in bilateral lungs. Almost all patients have thickened interlobular septa. The patients generally have multilobar involvement bilaterally more commonly in lower and upper lobes.

Approximately 4 - 10 days after infection, most lesions were absorbed with a reduced extent and decreased density with the formation of fibrotic stripes. Lesions can also become worse starting with ground-glass opacities and areas of consolidation in the center of opacities on day 2 progressing to multiple lungs on day 6 with thickened interlobular septa by day 9 . The lesions can get worse before getting better. CT scan of the chest shows the greatest severity approximately $9-10$ days after the onset of initial symptoms [25].

The bilateral patchy shadows or ground-glass opacities from various studies are summarized in Figure 5.

\section{Hospital and Inpatient Trends, Morbidity, Co- morbidities and Mortality}

Patients infected with COVID-19 and had multiple medical comorbidities were reported to have higher morbidity and mortality. As per the analysis by Wang et al involving 138 cases of COVID-19, approximately $46 \%$ of them have comorbidities, and more importantly, patients admitted to the intensive care unit had a higher number of comorbidities (72\%) compared to who did not (37\%) [34]. As per the meta-analysis of Yang et al involving 46,248 COVID-19 infected patients, the most prevalent comorbidity was hypertension with a range of 10 $24 \%$, diabetes mellitus with a range of $2-14 \%$, cardiovascular diseases with a range of $129 \%$ and respiratory diseases around $2 \%$. As per the final analysis, underlying hypertension, cardiovascular disease and respiratory system disease might be risk factors in patients with severe infection compared to patients with known severe infection [35]. Other studies discussing about comorbidities are summarized in Table 2.

In a case study with 99 patients performed by Chen et al, $17 \%$ of diagnosed patients developed ARDS, $13 \%$ required non-invasive respiratory support, $4 \%$ needed invasive ventilation and 3\% needed extracorporeal membrane oxygenation (ECMO) [15].

In a review by Tian et al, approximately $1 \%$ of patients died from COVID-19 out of 262 patients, all of whom had respiratory failure and were above the age of 50 [13]. Yang et al described that $2.6 \%$ of 54,406 in the Hubei province in China died from coronavirus vs. $0 \%$ of 499 patients diagnosed in Wenzhou city up until February 15, 2020 [18]. These numbers show that there is a regional difference in mortality of COVID-19 as the Wenzhou province has more resources than the former. Yang et al estimated the overall adjusted case fatality rate (CFR) among confirmed patients to be $3 \%$ with a sample size of 8,866 [36].

The course of hospitalization, morbidity and mortality are summarized in Figure 6.

\section{Clinical Scores}

COVID-19 causes increased morbidity and mortality in pa- 
Table 2. Studies Discussing About Comorbid Conditions and Mortality

\begin{tabular}{llll}
\hline Study & Number of patients (n) & Co-morbid conditions & Mortality \\
\hline Guan et al [31] & 1,099 & HTN: $165(15 \%)$ & $15(0.4)$ \\
& & CVD: $27(2.5 \%)$ & \\
& & DM: $81(7.4 \%)$ & \\
Huang et al [14] & 41 & HTN: $6(15 \%)$ & $6(15 \%)$ \\
& & CVD: $6(15 \%)$ & \\
& & DM: $8(20 \%)$ & $11(11 \%)$ \\
Chen et al [15] & CKD: NA & HTN: NA & \\
& & CVD: $40(40 \%)$ & DM: $12(12 \%)$ \\
\hline
\end{tabular}

HTN: hypertension; DM: diabetes mellitus; CVD: cardiovascular disease; CKD: chronic kidney disease; NA: not available.

tients who are elderly with several comorbidities. MuLBSTA score is an early warning model for predicting morbidity in viral pneumonia in 90 days as summarized in Table 3. It has a sensitivity of $77.6 \%$ and specificity of $77.8 \%$. It has better predictive ability than CURB-65 (confusion, blood urea nitrogen, respiratory rate, blood pressure and age greater than 65 years) [37].

\section{Classification}

$\mathrm{Xu}$ et al performed high-resolution CT scan on 50 patients admitted with SARS-CoV-2. It was classified into four types, as summarized in Table 4 [12]. Tian et al analyzed 262 cases of
RT-PCR confirmed COVID-19 in China, which was classified into three types, as summarized in Table 4 [13].

\section{Treatment}

\section{General measures}

An outbreak of a novel coronavirus (COVID-19 or 2019-CoV) infection causes significant morbidity and mortality. Coronavirus-specific treatments and antiviral treatments were very useful for the treatment of SARS and MERS and should be considered as potential treatments for COVID-19 [17]. There

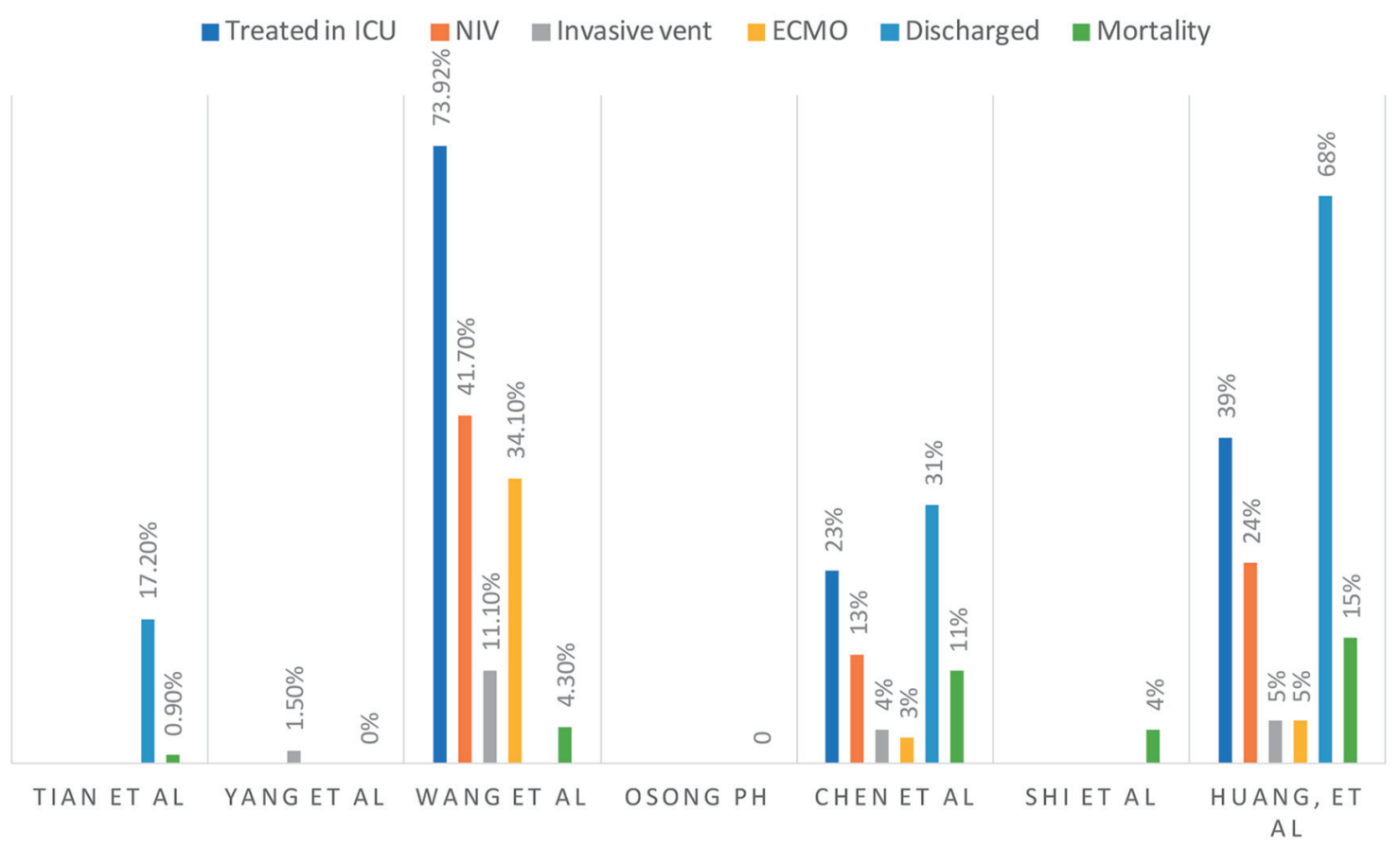

Figure 6. Course of hospitalization. 
Table 3. MuLBSTA Score

\begin{tabular}{ll}
\hline Multilobar infiltrate & 5 points \\
Lymphocyte count less than $0.8 \times 10^{9} / \mathrm{L}$ & 4 points \\
Bacterial coinfection & 4 points \\
Acute smoker & 3 points \\
Hypertension & 2 points \\
Age greater than or equal to 60 & 2 points \\
\hline
\end{tabular}

For in-hospital mortality, score 0 - 11 is low risk, score greater than or equal to 12 is high risk.

is an emergent need for other treatment options and a review of the literature for alternate treatment to control the disease mentioned below.

\section{Vitamins/antioxidants}

Multiple vitamin supplements and antioxidants can be considered to reduce the risk of infection. Vitamins A, B, thymosin alpha-1, thymopentin can be promising options for the adjunctive treatment of coronavirus and the prevention of lung infection [17]. Vitamin C supplementation might decrease the susceptibility to respiratory infections, as three human controlled clinical trials showed a lower incidence of pneumonia in supplemented groups [17]. Decreased vitamin D and E in calves had been reported to cause the infection of bovine coronavirus [17]. It could be another therapeutic option for this virus. Selenium with ginseng stem-leaf saponins could induce an immune response to a live bivalent infectious bronchitis coronavirus vaccine in chickens. Selenium supplementation could be a possible choice for the treatment [17]. Zinc and pyrithione combination at low concentrations can inhibit the replication of SARS coronavirus (SARS-CoV) [17].

\section{Interferons (IFNs)}

Type I IFNs, including IFN-B, could inhibit the replication of SARS-CoV and can be potent inhibitors of MERS-CoV replication in vitro. Still, no in vivo experiments have been performed [17]. IFN treatment was used in $96 \%$ of patients [18].
IFN- $\alpha$ vapor inhalation was administered at a dose of 5 million units for adults, two times/day for no longer 10 days [38].

\section{Chinese medicine}

Glycyrrhizin, baicalin and ginseng are all Chinese medicinal treatments that can help enhance host immunity against COVID-19 infection. They have been found to inhibit SARS-CoV in vitro [17].

\section{Spike (S)-protein angiotensin-converting enzyme (ACE)-2 blockers}

COVID S-protein uses ACE-2 as a sole receptor for entry into human cells. Monoclonal antibody neutralizes SARS-CoV and inhibits syncytia formation between cells expressing the S-protein and ACE-2 receptor [17]. Chloroquine is a potent SARS-CoV inhibitor through interfacing with ACE-2 [17]. Chloroquine is a potent SARS-CoV inhibitor through interfacing with ACE-2 [17]. Gao et al described chloroquine as a cheap and safe drug available for more than 70 years, which has been shown to have apparent efficacy and decent safety against pneumonia associated with COVID-19 in multicenter trials performed in China. As per the review of results from 10 hospitals and more than 100 patients, they showed that chloroquine phosphate is superior to control in decreasing the exacerbation of COVID-19 pneumonia. The anti-inflammatory and antiviral property of chloroquine may be responsible for its potent efficacy against COVID-19 pneumonia [39].

Chloroquine phosphate is orally administered at a dose of $500 \mathrm{mg}$ for adults, two times/day. Chloroquine was found to block SARS-CoV-2 infection at low micromolar concentration, with a half-maximal effective concentration (EC50) of $1.13 \mu \mathrm{M}$ and a half-cytotoxic concentration (CC50) greater than $100 \mu \mathrm{M}$ [40]. Emodin or promazine blocks interaction between S-protein and ACE-2, therefore, it could abolish SARS$\mathrm{CoV}$ infection by being a competitive inhibitor [17].

\section{Anti-virals}

Morgenstern et al have shown that ribavirin + IFN-B combi-

Table 4. Classification of Disease Based on Signs, Symptoms and Imaging

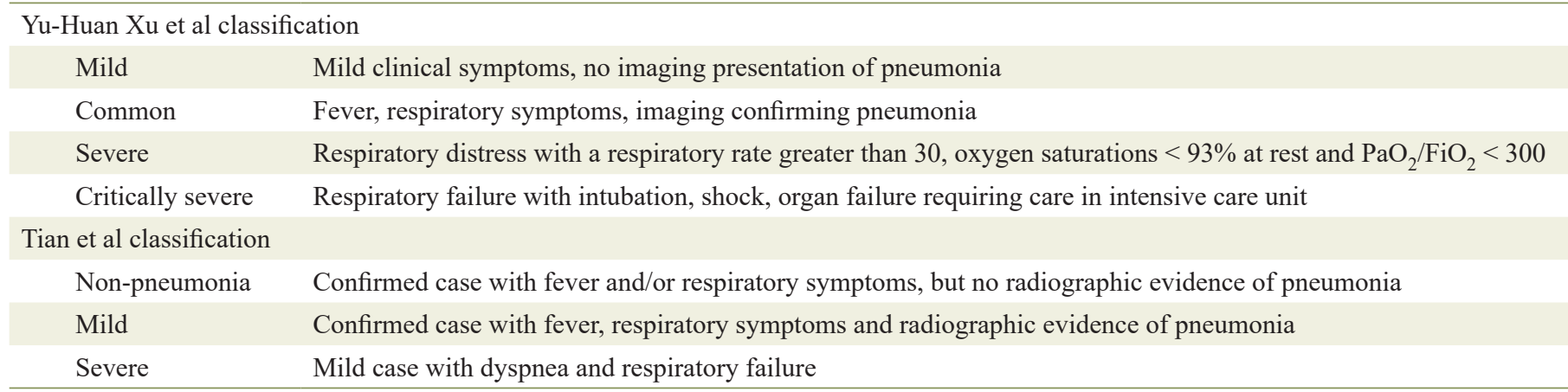


nation has shown to synergistically inhibit the replication of SARS-CoV in animal and human cell lines [41]. Kim et al have reported a case of MERS-CoV successfully treated with triple combination therapy with lopinavir/ritonavir, ribavirin and IFN-alpha2a therapy in South Korea [42]. Remdesivir has been reported to inhibit human and zoonotic coronavirus in vitro and restrains SARS-CoV in vivo [17]. Remdesivir + IFN-B was found to be superior to lopinavir/ritonavir + IFN-B therapy against MERS-CoV in vitro and in vivo. Yamamoto et al have found that nelfinavir could strongly inhibit the replication of SARS-CoV [43]. Akerstrom et al have reported that organic nitric oxide could significantly inhibit the replication cycle of SARS-CoV in a concentration-dependent manner and could be taken via inhalation [44].

Favipiravir is a drug currently undergoing testing to combat COVID-19. It was approved for the treatment of novel influenza in China. Favipiravir is an RNA-dependent RNA polymerase (RdRp) inhibitor. It inhibits the replication of RNA viruses like noro, arena, flavi, alpha, bunya, filo groups. Therefore, favipiravir may have potential antiviral action on SARS-CoV-2, which is an RNA virus. A clinical trial involving 80 patients has shown that favipiravir had more potent antiviral action than that of lopinavir/ritonavir. It had significantly fewer adverse events than the lopinavir/ritonavir group [38].

Remdesivir is a drug currently undergoing testing to combat COVID-19. Remdesivir is a nucleoside analog and a broad-spectrum antiviral $[3,38]$. Animal experiments indicated that remdesivir could effectively reduce the viral load in lung tissue of mice infected with MERS-CoV, improve lung function and alleviate pathological damage to lung tissue [38]. Wang et al found that remdesivir potently blocks SARS-CoV-2 infection at low-micromolar concentrations and has a high selectivity index (EC50: $0.77 \mu \mathrm{M}$; CC50 > $100 \mu \mathrm{M}$; SI > 129.87) and had in vitro activity against SARS-CoV-225 [45]. Holshue et al reported that remdesivir yielded promising results in the treatment of a patient with COVID-19 in the United States. A recent randomized controlled trial (RCT) is being performed [46]. It may also be possible to enhance the protective host immune response to infection [2].

Darunavir is a second-generation HIV-1 protease inhibitor. On February 4, 2020, researchers in China announced that darunavir inhibited SARS-CoV-2 infection in vitro [38].

\section{Type II transmembrane serine protease (TMPRSS2) in- hibitors}

SARS-CoV-2 uses the cellular protease TMPRSS2 receptor, SARS-CoV receptor and ACE-2 for entry into target cells as mentioned by Hoffmann et al. A TMPRSS2 inhibitor would block entry and thus constitute a treatment option [47].

Imatinib has anti-coronal activity primarily because it inhibits the fusion of virions with the endosomal membrane [38].

Arbidol is orally administered at a dose of $200 \mathrm{mg}$ three times a day in adults and able to inhibit SARS-CoV-2 infection in vitro in a clinical study.
Lopinavir/ritonavir is administered $400 \mathrm{mg} / 100 \mathrm{mg}$ for adults, two times a day for no longer than 10 days. Stockman et al reported to inhibit SARS-CoV reproduction in vitro $[3,48]$.

Ribavirin is administered intravenously at a dose of 500 $\mathrm{mg}$ for adults, 2 to 3 times daily, in combination with IFN- $\alpha$ or lopinavir/ritonavir. Chu et al suggested that patients treated with the combined therapy had a lower risk of ARDS and death in patients with SARS [49].

\section{Steroids}

Steroids increase viral shedding in patients with MERS-CoV, so WHO advised against their use in COVID-19 other than patients with ARDS [50]. According to current WHO guidelines, they do not recommend corticosteroid use as it did not reduce mortality and potentially delayed viral clearance [3].

\section{Probiotics}

Patients who have respiratory tract infections can have coexisting gut dysfunction. With more severe infections, there is a lung-gut cross-connection. This mechanism might also happen with COVID-19 infection, hence identifying and targeting gastrointestinal microbes can be a new treatment option or at least adjuvant treatment choice [19].

\section{Cepharanthine (CEP)}

It has profound antiviral activity, and there have been previous reports on its inhibitory effect on both SARS-CoV and previous strains of coronaviruses. It can inhibit 2019-nCoVr at a low concentration. Compared to regular infections without drug treatment, the viral RNA yields were significantly lower in vitro when using CEP; thus, our data suggest that CEP can potently inhibit coronavirus infection at viral entry and postentry phases [51]. CEP has low toxicity in animals and has no significant side effects in humans [51].

Mefloquine is an antimalarial drug found to have antiviral activity against both MERS-CoV and SARS-CoV in vitro [51]. No in vivo trials have been performed.

Selamectin is a topical broad-spectrum anti-parasitic in cats and dogs to control fleas, heartworms, hookworms, roundworms, etc. The antiviral mechanism is unknown, but selamectin could be a 2019-nCoVr specific inhibitor [51]. No in vivo trials have been performed.

Mechanism of action of CEP, mefloquine and selamectin is unknown. All possible therapeutic options are summarized in Table 5.

\section{Combat Pandemic}

The primary mode of transmission is via respiratory droplets with the most significant risks of transmission within 3 feet but up to 6 feet [33]. Portable radiography should be used to limit 
Table 5. Potential Therapeutic Options for COVID-19

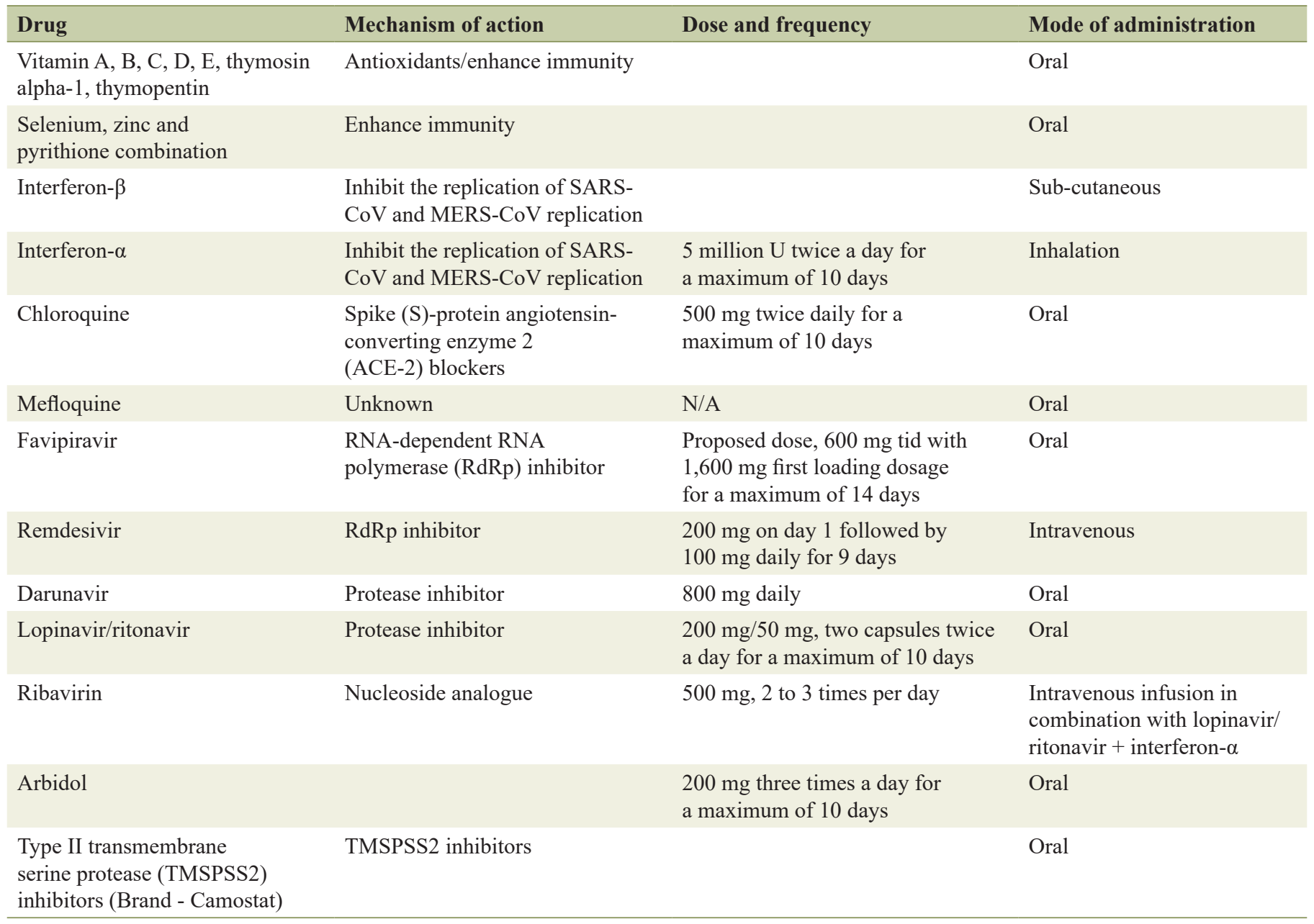

patient transportation [33]. Hospital care workers are recommended to wear full isolation gown with N95 mask or higher, disposable gloves, eye protection with goggles, with a face mask in front of goggles when caring for patients [33]. Surfaces of CT, MRI machines, ultrasound probes, blood pressure cuffs and mouse/keyboards of radiologic equipment should be disinfected with soap or alcoholic-based disinfectant [33]. Zhang et al stated that viral nucleic acid was found in stool samples from the patients who are suffering from COVID-19 pneumonia. So fecal-oral transmission is also possible. Hence, more consideration is given to hand hygiene, disinfection of contaminated surfaces as well as patient's stools and vomitus [52]. Close contact tracing and longitudinal surveillance through serial nucleic acid tests are essential in combating disease as asymptomatic carriers play a significant role in spreading the disease [23].

Effective management and treatment play a very crucial role, starting from identifying appropriate treatment and curing patients. COVID-19 imposes a significant public health concern as it became "once in a century pandemic" [53] due to its severe contagious transmission. Effectively identifying and treating one patient can help in preventing the development of several patients in the community.

\section{An action plan for inpatient care}

An action plan needs to be implemented in every organization to combat the disease at an early stage.

\section{The entrance of the hospital}

Patients should be offered to wear a nasal mask irrespective of symptoms when they visit the hospital.

\section{Triage in the emergency room}

It is essential to take travel history for every individual regardless of whether they are having symptoms suspicious for COVID-19 either to a different state or a different country. The second question is if they have any symptoms of cough either dry or with expectoration, increasing shortness of breath, con- 
gestion, fever, chest pain, headaches, generalized body aches and pains. The third question is contact with a patient with a confirmed coronavirus infection.

Drills and emergency preparedness about COVID-19 should be performed in all health care facilities involving providers who will be in touch with COVID-19 suspected patients. As escalating infection control in a health care setting can effectively prevent health care providers in contracting virus. According to Cheng et al, 2020, a bundled approach involving active and enhanced laboratory surveillance, early airborne isolation, contact tracing with unprotected exposure, rapid testing completely prevented nosocomial transmission of COVID-19 [53].

\section{In the emergency department}

If the patient responds yes to the above questions, health care personal entering the room should be appropriately wearing personal protective equipment to encounter a patient suspected COVID-19. It is crucial as the disease spread among healthcare providers will result in the rapid spread of the virus, thus increasing the morbidity and mortality. Once the patient is identified as a suspect of COVID-19 with presenting symptoms of fever, cough, congestion, chest pain, nausea and generalized body aches, they should be placed in a negative pressure isolation unit. The emergency room physician should order basic labs, including complete blood count (CBC), including a differential (CBC), complete metabolic panel (CMP), respiratory viral panel and a portable chest X-ray to rule out other etiologies. If other etiologies are ruled out and the patient is suspected of having COVID-19, the local health department should be notified, and PCR testing is recommended.

\section{Floor isolation room}

The patient should be transported to a negative pressure isolation room in the hospital. All isolation rooms should have negative air pressure and specially filtered air, containing and eliminating the circulation of the virus in the air. All staff should be well educated on the use of cleaning supplies and appropriate cleaning methods. All team members involved in patient care should receive regular education on the use of personal protective equipment. We should continuously monitor the United States Centers for Disease Control and Prevention (CDC) guidelines and adopt best practices as sooner they become available if possible health care professionals should be able to use a robotic mode of delivering medication and checking vitals to prevent the spread of the disease. This method helped in containing the disease in patients treated at China, in Washington DC.

\section{Health care team}

An emergency COVID-19 response team should be prepared in every hospital comprising of a hospitalist, infectious disease specialist and pulmonary/critical care physician to help with managing patients daily. All the essential up-to-date changes in treatment and management should be delivered to all the health care professionals daily in that hospital and to the community to help in treating other patients.

\section{Educating patients and the general population}

The mode of transmission is when a patient with COVID-19 coughs or exhales, they release droplets of fluid, which is infected, and most of these droplets fall nearby objects such as telephones tables and desks as well as other equipment. The public can catch the disease by touching these contaminated objects, and later touching the nose eyes or mouth. Notably, this is called transmission through fomites [54]. Patients can catch it by breathing in droplets if they are standing within $1 \mathrm{~m}$ of COVID-19 patients. They should be visited restrictions at all facilities encouraging people to visit patients by a telephone or electronically. We should also encourage people coming to the health care facilities for testing/treatment to limit the number of people who accompanied them. Since the virus causes significant mortality in older adults with significant comorbidities, they should be more restrictions placed on nursing homes such as no visitor policies in a high-risk environment. We should encourage social distancing, which means avoiding crowds and staying 6 feet away from other people as much as possible. We should also cancel or postpone all nonessential community events. All travel should be avoided unless absolutely necessary particularly to highly endemic zones of COVID-19. According to Wang et al, those having had close contacts with infections are currently being asked to receive medical observation and quarantine for 14 days [20].

\section{Difference between influenza and COVID-19}

Influenza and COVID-19 differ by multiple means. The first, only $1 \%$ of reported cases are asymptomatic and most patients develop symptoms within 2 days from COVID-19. With influenza, people who are infected might not get sick be due to herd immunity developed over the years [55]. The second difference is that COVID-19 causes more severe illness than influenza as it is a new virus and community have not developed any immunity, which makes more people susceptible to severe infection [5]. Globally, COVID-19 mortality is 3.4\% compared to influenza with mortality of less than $1 \%$ [5]. Third, no vaccines are there for COVID-19 at present, unlike seasonal flu which has a vaccine. Currently, more than 20 vaccines are in the clinical trial stage. Fourth, contact tracing and containment will possibly help for COVID-19 compared to influenza [55]. These are the reasons why WHO recommends "everything we can do to contain the virus" suggests a comprehensive approach to treat COVID-19.

\section{An action plan for outpatient care}

Screening should start in the outpatient setting with patients who should undergo infrared temperature detection before en- 


\section{Table 6. Model From Wuhan, China}

Phase 1 An early phase of the epidemic when few prevention and control measures were implemented. $\mathrm{R}_{0}$ was 3.1 .

Phase 2 Public transportation to and from Wuhan, as well as public transportation within Wuhan, were stopped. While gathering events inside Wuhan was banned, quarantine and isolation were gradually established in Wuhan. $\mathrm{R}_{\mathrm{t}}$ was 2.6.

Phase 3 New infectious disease hospitals and mobile cabin hospitals came into service, and many medical and public health teams from other provinces and cities in China arrived in Wuhan. The quarantine and isolation at the community level were further enhanced. $\mathrm{R}_{\mathrm{t}}$ decreased to 1.9 .

Phase 4 The peak of public health restrictions in Wuhan, China. $R_{t}$ became 0.9 .

$\mathrm{R}_{0}$ : metric in epidemiology used to describe the transmissibility of infectious agents; $\mathrm{R}_{\mathrm{t}}$ : reproduction number at a particular point of time.

tering a health care facility. This type of measurement detects the temperature of the patient's head, displayed on the device [29]. According to Zhang et al, four criteria should be used for screening patients for COVID-19: 1) coming from the epidemic area and having respiratory symptoms; 2) being part of a cluster of patients with fever and respiratory symptoms; 3 ) contact with a patient with a confirmed coronavirus infection; or 4) a temperature above $37.3^{\circ} \mathrm{C}\left(99.1^{\circ} \mathrm{F}\right)$ [29]. Contact tracing and testing all the suspected contacts at an early level and isolating them in isolation wards will help in halting disease at the early stages. Identifying and treating the entire community plays a pivotal role than detecting and single patients in this epidemic. Testing and identifying individuals even if they have an uncomplicated upper respiratory tract should be advised [50].

Medical professionals treating these patients should take the following precautions including: 1) wearing disposable work caps; 2) wearing protective glasses or face masks (antifog type); 3) wearing medical protective masks (N95); 4) wearing protective clothing or isolation clothing; 5) wearing disposable latex gloves (double layered); 6) wearing disposable shoe covers; and 7) strictly implementing good hand hygiene.

\section{Discussion}

In everyday clinical practice, the most common phrase heard is COVID-19, also called as novel coronavirus. As of March 16, 2020, a total of 168,019 confirmed cases in 148 countries were reported. Among 87,002 more than 3,400 deaths of COVID-19 have been reported to WHO outside of China, and it exceeded China's death rate [1]. While cases from China have been decreasing according to the recent available data, the reported cases from outside of China have been increasing at an alarming rate. The number of cases reported were nine times more in the rest of the world compared to China since January 22, 2020 [12]. Reviewing the history of the disease, as of December 2019, a total of 41 cases of pneumonia of unknown origin have been confirmed in the city of Wuhan. Most of them visited local fish and wild animal market within 30 days of infection in Wuhan, Hubei province, China [5]. It was first identified and announced as a new coronavirus $(2019 \mathrm{nCoV})$ by a scientific team lead by Dr. Jianguo Xu, an academician of the Chinese Academy of Engineering [51]. In human coronaviruses, there is a spectrum of the viruses, which can cause infections ranging from the common cold to fatal diseases including, SARS and MERS, which are zoonotic. The unique pathogenesis of COVID-19 compared to SARS and MERS is, it mainly affects the lower respiratory tract as well as the involvement of the gastrointestinal system causing diarrhea, compared to few patients with MERS and SARS having diarrhea [25].

It was estimated that COVID-19 has a reproductive rate ranging from 2.24 (95\% CI: $1.96-2.55)$ to 3.58 (95\% CI: 2.89 - 4.39), which is correlated to eight-fold to two-fold rise in reporting rate [56]. Imai et al provided the first estimation of the reproduction factor, using $\mathrm{R}_{0}$ of 2.6 and based on the number of cases in China and those detected in other countries [57]. Other authors estimated $\mathrm{R}_{0}$ to be $3.813,6.4714,2.215$ and 2.6816 [20]. According to Wang et al, the model used to calculate $R_{0}$ was assumed of the model from Wuhan, China, as summarized in Table 6. The model used to calculate $\mathrm{R}_{0}$ assumed that there were no new transmissions from animals, no differences in individual immunity, the time-scale of the epidemic is much faster than specific times for demographic processes (natural birth and death), and there are no differences in natural births and deaths [20]. Assuming the epidemic continues to develop with $\mathrm{R}_{0}=1.9,2.6$ and 3.19 from December 1, 2019, the number of infections will continue to rise. By the end of February 2020, COVID-19 cases would be 11,044, 70,258 and 227,989 in Wuhan, China with $\mathrm{R}_{0}=1.9,2.6$ and 3.1, respectively [20]. According to Read's research, $\mathrm{R}_{0}$ for COVID-19 outbreak is much higher compared with other emergent coronaviruses [58]. We see a decreased trend in $R_{t}$ as discussed in Table 6 with effective implementation of public health measures to control the spread of the disease.

After reviewing cases from Hubei province, severe COVID-19 cases occur mostly in men, and many of them do have comorbid conditions, including cerebrovascular, cardiovascular and diabetes. Several sequelae were seen including, coagulation activation, cellular immune deficiency, hepatic and kidney injury, secondary bacterial infection and myocardial injury. Lymphopenia and sustained inflammation seen in patients with severe disease and death are most likely secondary to antibody-dependent enhancement (ADE) of COVID-19 due to previous exposure to other coronaviruses [30]. Especially this kind of pattern is also seen in patients who had SARS during an epidemic in 2003 [40].

\section{Conclusion}

COVID-19 is a significant clinical threat to the general popula- 
tion and health care workers worldwide. Unfortunately, knowledge about the novel virus is limited, causing lots of concern and panic. To decrease morbidity and mortality associated with COVID-19, public health and infection control measures are urgently required to limit the global spread of the virus. All efforts should be made to slow the spread of the illness in order to provide time for health care systems and the general public to prepare and to develop timely diagnostics, therapeutics and vaccines. Finally, although the improvement of internet communication enhances information dissemination, it also has the potential to spread misinformation. Hence, we need to educate the public to follow information from a reliable website such as the CDC in the US. There are several unanswered questions at present in the management of COVID-19. Even though several case studies, RCTs and systemic reviews were done, there is no clarity regarding the exact pathogenesis of the disease, duration of shedding of virus and the possibility of other contaminant viral infections including influenza as well as secondary bacterial infections. The pandemics like COVID-19 put stress on every part of society, posing significant treat to international health and the economy. Several vaccines and promising treatments are being tested on clinical trials. However, the rising number of infected people, as well as mortality from it and the highly contagious nature of COVID-19 with a prolonged incubation period and asymptomatic carriers shredding the virus, makes it challenging to contain the spread. At present, handwashing, isolating and quarantine patients who are exposed or infected with the virus, disinfecting the contaminated surfaces as well as extensive public health measures such as avoiding large group meetings, closure of schools, restricting travel are being implemented by different countries to curb the spread of this virus. Hopefully, we develop an effective vaccine and treatment as soon as possible. Continued clinical trials are required to understand the pathogenesis of COVID-19 to tackle the disease better and to decrease morbidity and mortality.

\section{Acknowledgments}

I thank all the authors who contributed in carrying out research.

\section{Financial Disclosure}

None to declare.

\section{Conflict of Interest}

None to declare.

\section{Author Contributions}

MB, GPM, MP, VG and SA were involved in data collection, review and preparation of the manuscript. MB and MP created figures/bar graphs. MB, SN, NMK and VMK involved in the analysis of data and final review the manuscript, preparation of tables. All of the authors reviewed the manuscript and agreed with the findings and interpretation.

\section{Data Availability}

PubMed, google scholar databases and in-press literature from google search. The authors declare that data supporting the findings of this study are available within the article.

\section{Abbreviations}

CDC: Centers for Disease Control and Prevention; WHO: World Health Organization; SARS: severe acute respiratory syndrome; MERS: Middle East respiratory syndrome; COVID-19: coronavirus disease 2019; RT-PCR: real-time reverse transcriptase polymerase chain reaction; $\mathrm{nCoV}$ : novel corona virus (coronavirus); $\mathrm{CI}$ : confidence interval

\section{References}

1. WHO website. https://experience.arcgis.com/experience/ 685d0ace521648f8a5beeee $1 \mathrm{~b} 9125 \mathrm{~cd}$.

2. The Atlantic news report from February 24, 2020. Accessed on February 25, 2020. https://www.theatlantic. com/health/archive/2020/02/covid-vaccine/607000/.

3. Peeri NC, Shrestha N, Rahman MS, Zaki R, Tan Z, Bibi $\mathrm{S}$, Baghbanzadeh M, et al. The SARS, MERS and novel coronavirus (COVID-19) epidemics, the newest and biggest global health threats: what lessons have we learned? Int J Epidemiol. 2020.

4. Lu R, Zhao X, Li J, Niu P, Yang B, Wu H, Wang W, et al. Genomic characterisation and epidemiology of 2019 novel coronavirus: implications for virus origins and receptor binding. Lancet. 2020;395(10224):565-574.

5. Chang L, Yan Y, Wang L. Coronavirus disease 2019: coronaviruses and blood safety. Transfus Med Rev. 2020.

6. Chan JF, Yuan S, Kok KH, To KK, Chu H, Yang J, Xing $\mathrm{F}$, et al. A familial cluster of pneumonia associated with the 2019 novel coronavirus indicating person-to-person transmission: a study of a family cluster. Lancet. 2020;395(10223):514-523.

7. Li Q, Guan X, Wu P, Wang X, Zhou L, Tong Y, Ren R, et al. Early transmission dynamics in Wuhan, China, of novel coronavirus-infected pneumonia. N Engl J Med. 2020;382(13):1199-1207.

8. Zhou P, Yang XL, Wang XG, Hu B, Zhang L, Zhang W, Si HR, et al. A pneumonia outbreak associated with a new coronavirus of probable bat origin. Nature. 2020;579(7798):270-273.

9. Xiao K, Zhai J, Feng Y, Zhou N, Zhang X, Zou JJ, Li N, et al. Isolation and Characterization of 2019-nCoV-like coronavirus from Malayan Pangolins. bioRxiv. 2020.

10. Liu P, Chen W, Chen JP. Viral metagenomics revealed sendai virus and coronavirus infection of Malayan Pan- 
golins (Manis javanica). Viruses. 2019;11(11):979.

11. Liu P, Jiang JZ, Hua Y, Wang X, Hou F, Wan XF, Chen $\mathrm{J}$, et al. Are pangolins the intermediate host of the 2019 novel coronavirus (2019-nCoV)? bioRxiv. 2020.

12. Xu YH, Dong JH, An WM, Lv XY, Yin XP, Zhang JZ, Dong L, et al. Clinical and computed tomographic imaging features of novel coronavirus pneumonia caused by SARS-CoV-2. J Infect. 2020;80(4):394-400.

13. Tian S, Hu N, Lou J, Chen K, Kang X, Xiang Z, Chen H, et al. Characteristics of COVID-19 infection in Beijing. J Infect. 2020;80(4):401-406.

14. Huang C, Wang Y, Li X, Ren L, Zhao J, Hu Y, Zhang L, et al. Clinical features of patients infected with 2019 novel coronavirus in Wuhan, China. Lancet. 2020;395(10223):497-506.

15. Chen N, Zhou M, Dong X, Qu J, Gong F, Han Y, Qiu Y, et al. Epidemiological and clinical characteristics of 99 cases of 2019 novel coronavirus pneumonia in Wuhan, China: a descriptive study. Lancet. 2020;395(10223):507513.

16. Kong I, Park Y, Woo Y, Lee J, Cha J, Choi J, Kim Y, et al. Early epidemiological and clinical characteristics of 28 cases of coronavirus disease in South Korea. Osong Public Health Res Perspect. 2020;11(1):8-14

17. Zhang L, Liu Y. Potential interventions for novel coronavirus in China: A systematic review. J Med Virol. 2020;92(5):479-490.

18. Yang W, Cao Q, Qin L, Wang X, Cheng Z, Pan A, Dai J, et al. Clinical characteristics and imaging manifestations of the 2019 novel coronavirus disease (COVID-19):A multicenter study in Wenzhou city, Zhejiang, China. J Infect. 2020;80(4):388-393.

19. Gao QY, Chen YX, Fang JY. 2019 Novel coronavirus infection and gastrointestinal tract. J Dig Dis. 2020.

20. Wang H, Wang Z, Dong Y, Chang R, Xu C, Yu X, Zhang $\mathrm{S}$, et al. Phase-adjusted estimation of the number of coronavirus disease 2019 cases in Wuhan, China. Cell Discov. 2020;6:10.

21. Lillie PJ, Samson A, Li A, Adams K, Capstick R, Barlow GD, Easom N, et al. Novel coronavirus disease (Covid-19): The first two patients in the UK with person to person transmission. J Infect. 2020.

22. Luo SH, Liu W, Liu ZJ, Zheng XY, Hong CX, Liu ZR, Liu J, et al. A confirmed asymptomatic carrier of 2019 novel coronavirus (SARS-CoV-2). Chin Med J (Engl). 2020.

23. Hu Z, Song C, Xu C, Jin G, Chen Y, Xu X, Ma H, et al. Clinical characteristics of 24 asymptomatic infections with COVID-19 screened among close contacts in Nanjing, China. Science China Life Sciences. 2020.

24. Marchand-Senecal X, Kozak R, Mubareka S, Salt N, Gubbay JB, Eshaghi A, Allen V, et al. Diagnosis and management of first case of COVID-19 in Canada: Lessons applied from SARS. Clin Infect Dis. 2020.

25. Lin C, Ding Y, Xie B, Sun Z, Li X, Chen Z, Niu M. Asymptomatic novel coronavirus pneumonia patient outside Wuhan: The value of CT images in the course of the disease. Clin Imaging. 2020;63:7-9.

26. Lippi G, Plebani M. Procalcitonin in patients with severe coronavirus disease 2019 (COVID-19): A meta-analysis. Clin Chim Acta. 2020;505:190-191.

27. Ruan ZR, Gong P, Han W, Huang MQ, Han M. A case of 2019 novel coronavirus infected pneumonia with twice negative 2019-nCoV nucleic acid testing within 8 days. Chin Med J (Engl). 2020.

28. Chen D, Xu W, Lei Z, Huang Z, Liu J, Gao Z, Peng L. Recurrence of positive SARS-CoV-2 RNA in COVID-19: A case report. Int J Infect Dis. 2020.

29. Zhang HW, Yu J, Xu HJ, Lei Y, Pu ZH, Dai WC, Lin F, et al. Corona virus international public health emergencies: implications for radiology management. Acad Radiol. 2020;27(4):463-467.

30. Shi H, Han X, Jiang N, Cao Y, Alwalid O, Gu J, Fan Y, et al. Radiological findings from 81 patients with COVID-19 pneumonia in Wuhan, China: a descriptive study. Lancet Infect Dis. 2020.

31. Guan WJ, Ni ZY, Hu Y, Liang WH, Ou CQ, He JX, Liu L, et al. Clinical characteristics of 2019 novel coronavirus infection in China. MedRxiv. 2020.

32. Chung M, Bernheim A, Mei X, Zhang N, Huang M, Zeng X, Cui J, et al. CT imaging features of 2019 novel coronavirus (2019-nCoV). Radiology. 2020;295(1):202207.

33. Kooraki S, Hosseiny M, Myers L, Gholamrezanezhad A. Coronavirus (COVID-19) outbreak: what the department of radiology should know. J Am Coll Radiol. 2020.

34. Wang D, Hu B, Hu C, Zhu F, Liu X, Zhang J, Wang B, et al. Clinical characteristics of 138 hospitalized patients with 2019 novel coronavirus-infected pneumonia in Wuhan, China. JAMA. 2020.

35. Yang J, Zheng Y, Gou X, Pu K, Chen Z, Guo Q, Ji R, et al. Prevalence of comorbidities in the novel Wuhan coronavirus (COVID-19) infection: a systematic review and meta-analysis. Int J Infect Dis. 2020.

36. Yang Y, Lu Q, Liu M, Wang Y, Zhang A, Jalali N, Dean N, et al. Epidemiological and clinical features of the 2019 novel coronavirus outbreak in China. medRxiv. 2020.

37. Guo L, Wei D, Zhang X, Wu Y, Li Q, Zhou M, Qu J. Clinical features predicting mortality risk in patients with viral pneumonia: the MuLBSTA Score. Front Microbiol. 2019; $10: 2752$

38. Dong L, Hu S, Gao J. Discovering drugs to treat coronavirus disease 2019 (COVID-19). Drug Discov Ther. 2020;14(1):58-60.

39. Gao J, Tian Z, Yang X. Breakthrough: Chloroquine phosphate has shown apparent efficacy in treatment of COVID-19 associated pneumonia in clinical studies. Biosci Trends. 2020;14(1):72-73.

40. The News report, https://www.thenewsminute.com/article/hyderabad-techie-coronavirus-traveled-bengaluru80-people-under-watch-119332.

41. Morgenstern B, Michaelis M, Baer PC, Doerr HW, Cinatl J, Jr. Ribavirin and interferon-beta synergistically inhibit SARS-associated coronavirus replication in animal and human cell lines. Biochem Biophys Res Commun. 2005;326(4):905-908.

42. Kim UJ, Won EJ, Kee SJ, Jung SI, Jang HC. Combination therapy with lopinavir/ritonavir, ribavirin and interferon- 
alpha for Middle East respiratory syndrome. Antivir Ther. 2016;21(5):455-459.

43. Yamamoto N, Yang R, Yoshinaka Y, Amari S, Nakano T, Cinatl J, Rabenau H, et al. HIV protease inhibitor nelfinavir inhibits replication of SARS-associated coronavirus. Biochem Biophys Res Commun. 2004;318(3):719-725.

44. Akerstrom S, Mousavi-Jazi M, Klingstrom J, Leijon M, Lundkvist A, Mirazimi A. Nitric oxide inhibits the replication cycle of severe acute respiratory syndrome coronavirus. J Virol. 2005;79(3):1966-1969.

45. Wang M, Cao R, Zhang L, Yang X, Liu J, Xu M, Shi Z, et al. Remdesivir and chloroquine effectively inhibit the recently emerged novel coronavirus $(2019-\mathrm{nCoV})$ in vitro. Cell Res. 2020;30(3):269-271.

46. Holshue ML, DeBolt C, Lindquist S, Lofy KH, Wiesman J, Bruce H, Spitters C, et al. First case of 2019 novel coronavirus in the United States. N Engl J Med. 2020;382(10):929-936.

47. Hoffmann M, Kleine-Weber H, Krueger N, Mueller MA, Drosten C, Pohlmann S. The novel coronavirus 2019 (2019-nCoV) uses the SARS-coronavirus receptor ACE2 and the cellular protease TMPRSS2 for entry into target cells. https://www.biorxiv.org/content/10.1101/2020.01.3 $1.929042 \mathrm{v} 1$.

48. Stockman LJ, Bellamy R, Garner P. SARS: systematic review of treatment effects. PLoS Med. 2006;3(9):e343.

49. Chu CM, Cheng VC, Hung IF, Wong MM, Chan $\mathrm{KH}$, Chan KS, Kao RY, et al. Role of lopinavir/ritonavir in the treatment of SARS: initial virological and clinical findings. Thorax. 2004;59(3):252-256.

50. Vetter P, Eckerle I, Kaiser L. Covid-19: a puzzle with many missing pieces. BMJ. 2020;368:m627.

51. Fan HH, Wang LQ, Liu WL, An XP, Liu ZD, He XQ, Song LH, et al. Repurposing of clinically approved drugs for treatment of coronavirus disease 2019 in a 2019-novel coronavirus (2019-nCoV) related coronavirus model. Chin Med J (Engl). 2020.

52. Researchers at Shenzhen Third People's Hospital. Fecalto-mouth transmission risk of new coronavirus (in Chinese). http://www.xinhuanet.com/2020-02/02/c 112552 0498.htm.

53. Cheng VCC, Wong SC, Chen JHK, Yip CCY, Chuang VWM, Tsang OTY, Sridhar S, et al. Escalating infection control response to the rapidly evolving epidemiology of the Coronavirus disease 2019 (COVID-19) due to SARSCoV-2 in Hong Kong. Infect Control Hosp Epidemiol. 2020:1-24.

54. https://www.who.int/docs/default-source/coronaviruse/ getting-workplace-ready-for-covid-19.pdf.

55. WHO Director-General's opening remarks at the media briefing on COVID-19 - 3 March 2020- https:/www. who.int/dg/speeches/detail/who-director-general-sopening-remarks-at-the-media-briefing-on-covid19---3-march-2020

56. Zhao S, Lin Q, Ran J, Musa SS, Yang G, Wang W, Lou $\mathrm{Y}$, et al. Preliminary estimation of the basic reproduction number of novel coronavirus (2019-nCoV) in China, from 2019 to 2020: A data-driven analysis in the early phase of the outbreak. Int J Infect Dis. 2020;92:214-217.

57. Imai N, Cori A, Dorigatti I, Baguelin M, Donnelly CA, Riley S, Ferguson NM. Report 3: transmissibility of 2019nCov. Reference Source. https://www.imperial.ac.uk/media/imperial-college/medicine/sph/ide/gida-fellowships/ Imperial-College-COVID19-transmissibility-25-012020.pdf.

58. Read JM, Bridgen JR, Cummings DA, Ho A, Jewell CP. Novel coronavirus 2019-nCoV: early estimation of epidemiological parameters and epidemic predictions. https:// www.medrxiv.org/content/10.1101/2020.01.23.2001854 9v2. 